\title{
Plaquetas: Papéis tradicionais e não tradicionais na hemostasia, na inflamação e no câncer
}

\author{
Platelets: Traditional and nontraditional \\ roles in hemostasis, inflammation and cancer
}

Ingrid Oliveira ${ }^{1,2}$, Manoel João Batista Castello Girão $0^{2,3}$

Misako Uemura Sampaio4, Maria Luiza Vilela Oliva ${ }^{4}$, Sheila Siqueira Andrade ${ }^{2,3}$

${ }^{1}$ Curso de Pós Graduação em Fisiologia Humana da Faculdade de Medicina do ABC (FMABC) - Santo André (SP), Brasil.

${ }^{2}$ Associação Beneficente de Coleta de Sangue de São Paulo (COLSAN) - São Paulo (SP), Brasil.

${ }^{3}$ Departamento de Ginecologia da UNIFESP - São Paulo (SP), Brasil.

${ }^{4}$ Departamento de Bioquímica da UNIFESP - São Paulo (SP), Brasil.

DOI: http://dx.doi.org/10.7322/abcshs.v38i3.21

\section{RESUMO}

A principal e mais conhecida função plaquetária ainda está relacionada à parada de sangramento após um dano vascular No entanto, plaquetas estão envolvidas em diversos processos, tais como iniciar e amplificar a inflamação, interagir com células da resposta imune, além de participar na progressão tumoral, angiogênese e metástase. Neste sentido, está claro que plaquetas apresentam funções no processo inflamatório e podem influenciar respostas imune, além de desordens plaquetárias autoimune e relacionadas a presença de auto-anticorpos após transfusões, como por exemplo, na lesão pulmonar aguda associada à transfusão. Após muita especulação, recentes observações têm estabelecido novos paradigmas relacionando plaquetas à biologia molecular. Plaquetas humanas contêm fatores de spliceossomo, incluindo pequenos RNAs nucleares, proteínas de splicing e pre-mRNA endógenos. Outro ponto importante é o controle do número de plaquetas circulantes, resultado do equilíbrio entre a produção e destruição dessas células. Assim, é proposto um processo de morte programada da célula anucleada que determina seu tempo de vida. Esse processo é alvo de especulações desde a década de 60 e ainda permanece em discussão. A noção geral de que plaquetas funcionais são importantes para o sucesso de processos hematogênicos corroboram com inovações experimentais e também ligam a processos de interação plaquetas-células tumorais e seu microambiente que regula a progressão maligna. Plaquetas contribuem na sobrevivência e disseminação de células tumorais. Desta forma, discutimos aqui os mecanismos pelos quais as plaquetas atuam na imunidade, na inflamação e no câncer, uma vez que estas pequenas células são mais versáteis do que se pensava.

Palavras-chave: plaquetas; inflamação; transfusão de sangue: câncer; hemostasia; processamento de RNA.

\section{ABSTRACT}

The principal and the most known function of platelets still remains stopping hemorrhage following vascular injury. However, platelets are involved in diverse processes such as triggering inflammation, participating in the immune response, besides tumor progression, angiogenesis, and metastasis. In this sense, it is becoming increasingly clear that platelets display inflammatory functions and can influence both innate and adaptive immune responses, such as autoimmune and alloimmune platelet disorders, and transfusion-related acute lung injury (TRALI). Despite much speculation recent observations have established new paradigms relevant to influence of platelets on molecular biology. Primary human platelets contain essential spliceosome factors including small nuclear RNAs, splicing proteins, and endogenous pre-mRNAs. Other point is, like all lineages of blood cells, the steady state number of mature platelets is the result of a balance between their production and destruction. Thus, it is proposed a programmed anuclear cell death delimits platelet life span is subject of speculation since the 1960s and has remained elusive. The general notion that functional platelets are important for successful hematogenous tumor metastasis dates more than 4 decades and has been corroborated in numerous experimental settings. The dynamic crosstalk between tumors and their microenvironment is increasingly recognized as a key regulator of malignant progression. These contributions of platelets to tumor cell survival and spread suggest platelets as a new avenue for research. Here, we discuss the mechanisms by which platelets contribute to immunity, inflammation, and cancer, since these small cells are more versatile than we once thought.

Keywords: blood platelets; inflammation; blood transfusion; neoplasms; hemostasis; RNA splicing 


\section{INTRODUÇÃO}

Células efetoras da hemostasia e altamente especializadas, de origem mieloide, plaquetas circulam no sangue como citoplastos anucleados em estado de repouso. Em resposta a sinais de ativação, seu fenótipo quiescente muda para uma célula efetora e versátil, desempenhando funções como adesão, agregação, formação do "tampão" hemostático. Além disso, participam de processos adicionais, desempenhando um papel chave em processos inflamatórios, de reparo vascular, tecidual e participam da modulação do sistema imunológico, como reações autoimune e desordens aloimunes (como, por exemplo, trombocitopenia imune, refratariedade transfusional, trombocitopenia aloimune fetal e neonatal e púrpura pós-transfusional) $)^{1}{ }^{\text {a }}$

Desde o início dos anos 2000 até hoje, novas observações e descobertas estabeleceram recentes paradigmas na função e na biologia molecular plaquetária. Há várias descobertas pertinentes às influências das plaquetas em processos considerados como não tradicionais: capacidade de sintetizar proteínas, mecanismos inesperados de splicing, processo de morte celular (anuclear) programada, envolvimento de plaquetas na sinalização de células-tronco, reparo vascular, processos tradicionais de interações com células endoteliais e com leucócitos (envolvendo mecanismos de adesão, agregação, formação do tampão hemostático e retração do coágulo em sítios de danos vasculares $)^{1-5}$.

Denis et $a l .{ }^{4}$ evidenciaram um inesperado complexo funcional de spliceossomo em plaquetas, um complexo que processa pre-mRNA no núcleo de outros tipos celulares. Os componentes do spliceossomo estão presentes no citoplasma de megacariócitos humanos e em pro-plaquetas (extensões dos megacariócitos). As plaquetas primárias humanas também contêm fatores de spliceossomo que incluem pequenos RNAs nucleares (herdados do megacariócito - célula de origem), proteínas de splicing e pre-mRNAs endógenos. ${ }^{\mathrm{b}}$

\section{ONTOGÊNESE PLAQUETÁRIA}

Há duas teorias propostas para a origem ou formação de plaquetas a partir de megacariócitos. A primeira teoria propõe que a fragmentação do citoplasma de megacariócitos, na medula óssea ou em leitos capilares pulmonares, gera plaquetas maduras e circulantes. Porém, existe um potencial problema com essa hipótese, pois há uma composição intracelular uniforme das plaquetas maduras formadas. Se esse processo é aleatório, 'como garantir que todo o conteúdo herdado do megacariócito será o mesmo para todas as plaquetas formadas?' A menos que esse processo seja estereotipado, não há garantia de que toda a maquinaria plaquetária será distribuída igualmente em cada plaqueta madura ${ }^{5}$

A segunda teoria, ou modelo de formação de plaquetas, propõe que megacariócitos diferenciados na medula óssea e no pulmão estendam-se multiplamente, com alongamento de suas extremidades, formando as pro-plaquetas (PPs) ou plaquetas reticuladas. Uma vez formadas as PPs, todo o conteúdo intracelular é transferido dos megacariócitos a essas estruturas, que posteriormente conduzem a migração para suas pontas via trilhas microtubulares, um regulado processo de translocação do seu conteúdo e de mudança conformacional. Desta maneira, podemos afirmar que plaquetas são formadas a partir das pontas das PPs as quais são mais densas e mais ativas no processo de formação do trombo hemostático do que plaquetas maduras, pois contêm um retículo endoplasmático grosseiro e uma carga maior de mRNAs. A determinação do número de PPs é útil para monitorar a trombopoiese e o turnover de plaquetas maduras ${ }^{6}$. As plaquetas maduras formadas circulam no sangue por aproximadamente 7-10 dias, período esse que pode ser menor, uma vez que essas células anucleadas sejam ativadas e depositadas em sítios de dano vascular, inflamatório, sequestradas pela microvasculatura e/ou, programadas por apoptose/morte programada anuclear ${ }^{7}$.

Os dois modelos de trombopoiese não são excludentes, porém existem evidências de que há um processo altamente regulado de translocação dos constituintes intracelulares dos megacariócitos para a formação das pro-plaquetas para finalmente a formação da plaqueta madura circulante. Estudos in vitro de diferenciação dos megacariócitos a partir de células progenitoras hematopoiéticas humanas e de ratos, dão suporte à segunda teoria de formação de plaquetas ${ }^{4,6}$.

Em 2007, utilizando a técnica de microscopia intravital Junt et al. ${ }^{9}$ observaram a formação de extensões de PPs na medula e em vasos sanguíneos sinusoidais de camundongos transgênicos que expressam trombopoetina ligada a GFP (do inglês, "green florescent protein"), onde aparentemente forças de cisalhamento aparecem para libertá-las das células mãe. Para corroborar com esses dados, Geddis e Kaushansky ${ }^{9}$ identificaram células circulantes com

a) Trombocitopenia imune': presença de anticorpos autorreativos e de linfócitos T citotóxicos que levam à destruição de plaquetas e a inibição da fragmentação periférica de megacariócitos.

Refratariedade transfusiona1': desenvolvimento de autoanticorpos pós transfusão.

Autoanticorpo ${ }^{1}$ : é um anticorpo produzido pelo sistema imune que atua contra uma ou mais proteínas do próprio indivíduo que o produziu. Os autoanticorpos tem as mesmas propriedades bioquímica e físico-química de outros anticorpos porém, reagem contra componentes do próprio organismo (proteínas celulares, DNA no núcleo).

Trombocitopenia aloimune fetal e neonatal: desenvolvimento de aloanticorpos HPA-específicos e subsequente trombocitopenia fetal e neonatal.

Púrpura pós-transfusional': Desenvolvimento de aloanticorpos induzidos por tranfusão e subsequente trombocitopenia.

b) Splicing": é uma modificação do RNA após a transcrição, no qual se pode remover íntrons e unir éxons, ou seja, é a retirada de íntrons de um mRNA precurssor para se obter um mRNA maduro funcional.

Spliceossomo : estrutura complexa com atividade catalítica responsável pelo splicing. É composto de ribonucleoproteínas ligadas a moléculas de RNA do tipo snRNA (RNA pequeno nuclear do inglês "small nuclear RNA").

c) Ontogênese ${ }^{8}$ : Em biologia celular descreve o desenvolvimento de vários tipos celulares num determinando organismo, ou curso de mudanças estruturais de uma determinada unidade celular até a sua plena forma desenvolvida e funcional. 
morfologia de PPs no sangue de animais, sugerindo a possibilidade da formação contínua de plaquetas maduras em vasos periféricos.

Achados adicionais dão suporte a essas observações, que datam de 1925, indicando que a contagem de plaquetas é mais alta em vasos pulmonares em comparação com aquela do sangue arterial pulmonar, sugerindo que PPs circulantes são processadas em plaquetas maduras no pulmão $0^{10-11}$.

Como a trombopoiese é alterada em doenças inflamatórias pulmonares, e quais as suas consequências, ainda é um processo desconhecido. Além disso, há mecanismos adicionais de geração de plaquetas na circulação periférica, que podem ser influenciados por danos inflamatórios ${ }^{12}$. Há evidências que o pulmão é um reservatório de megacariócitos, além de ser um local de processamento de PPs. Megacariócitos são descritos como células poliplóides e que se acumulam em pulmões de humanos e roedores ${ }^{13,14}$

\section{RECEPTORES E COMPARTIMENTOS PLAQUETÁRIOS}

Plaquetas estão envolvidas em processos dinâmicos como a hemostasia, inflamação, imunidade e câncer, processos que necessitam de uma série coordenada de eventos que envolvem receptores de membrana, sinais bidirecionais intracelulares com liberação de proteínas e de fatores inflamatórios ${ }^{1,15,16}$.

Os receptores plaquetários estão na vanguarda das pesquisas recentes, e grandes avanços foram feitos a fim de compreender suas funções moleculares e o curso de suas vias de sinalização.

Estudos in vitro e in vivo, principalmente em modelos animais, sobre as funções dos receptores de superfície plaquetária, incluindo a inibição farmacológica por antagonistas específicos, têm ajudado a revelar novos mecanismos de como a propensão trombótica e hemorrágica das plaquetas é controlada em processos fisiopatológicos ${ }^{15}$.

Uma grande variedade de receptores transmembranares cobre a membrana das plaquetas, incluindo muitas integrinas $\left(\alpha_{\mathrm{IIb}} \beta_{3}\right.$, $\alpha_{2} \beta_{1}, \alpha_{5} \beta_{1}, \alpha_{6} \beta_{1}, \alpha_{v} \beta_{3}$ ), receptores ricos em leucina (LRR) (glicoproteína [GP] Ib/IX/V, receptores Toll-like ), receptores acoplados à proteína $\mathrm{G}$ com sete domínios transmembrânicos (GPCR) (PAR-1, PAR-3 e PAR-4 receptores ativados por proteases - principalmente trombina, P2Y1 e P2Y12 receptores de ADP, receptores prostanóides - TPA, TPB - e receptores TXA2), proteínas pertencentes à superfamília das imunoglobulinas (GP VI, FcgRIIA), receptores do tipo lectina (P-selectina), receptores tirosina-quinase (receptor de trombopoietina, Gas-6, efrinas e quinases Eph) e uma variedade de outros tipos (CD63, CD36, receptor do tipo TNF, entre outros) ${ }^{15-18}$.
Muitos destes receptores são encontrados em outros tipos celulares, mas alguns são apenas expressos em plaquetas, como a P-selectina (C-type lectin receptors). Neste cenário, está bem estabelecido que os principais receptores plaquetários têm um papel proeminente na função hemostática, permitindo interações específicas e funcionais com proteínas adesivas vasculares e com seus agonistas solúveis. Além disso, é cada vez mais reconhecido que esses receptores estão envolvidos em outros processos não menos importantes como inflamação, crescimento tumoral, metástase e resposta imune $e^{1,15,16,19}$.

Internamente, as plaquetas contêm um citoesqueleto, um sistema tubular denso, poucas mitocôndrias, grânulos de glicogênio, grânulos de estocagem do tipo alfa e denso, peroxissomos, mRNAs, complexo de spliceossomo, proteassomo e ubiquitina, bem como outras estruturas ${ }^{4,15}$.

Os grânulos $\alpha$-mantêm as proteínas relevantes para a função hemostática, como o fator de von Willebrand (vWF), fibrinogênio, P-selectina, PECAM-1, CD40 (CD154), fator 4 plaquetário, $\beta$-tromboglobulina, trombospondina, fator de crescimento derivado de plaquetas (PDGF), Fator V, bem como um estoque de GP IIb/IIIa $(\alpha \operatorname{IIb} \beta 3)$. Porém, quando o estímulo é muito intenso e esse estoque proteico/proteínico é consumido, as plaquetas iniciam um processo de síntese de proteínas através de seus mRNAs herdados da célula de origem, os megacariócitos ${ }^{4,15}$.

Os grânulos densos, por outro lado, são ricos em nucleotídeos (ADP e ATP), serotonina, histamina, pirofosfato e cálcio. Após a ativação, o conteúdo dos grânulos é liberado lentamente para promover ainda mais a adesão e agregação plaquetária ${ }^{15,17}$.

Diante dessas estruturas internas plaquetárias, a principal função das plaquetas é a de impedir a perda de sangue após o trauma do tecido e a exposição da matriz subendotelial ${ }^{20}$. No entanto, a fronteira entre o fisiológico (hemostasia) e o patológico (trombose) é muito estreita, já foi reconhecido o papel das plaquetas no desenvolvimento da aterotrombose, a principal causa de morte no mundo, devido ao aumento na expectativa de vida, a problemas relacionados a mudanças socioeconômicas e a urbanização ${ }^{21}$. A contribuição das plaquetas para o crescimento do trombo é espacial, ou seja, plenamente dependente da sua localização no interior da circulação sanguínea ${ }^{15,21,22}$. A participação das plaquetas na hemostasia e trombose têm sido amplamente investigadas nas últimas décadas. As pesquisas tradicionais nesta área utilizam técnicas comuns para o estudo de processos bioquímicos, da biologia celular e molecular plaquetária, e vêm proporcionando uma valiosa visão sobre os elementos e os sinais que regulam a ativação, adesão e agregação plaquetária. As técnicas de imagem com matriz fluorescente e sondas quimioluminescentes permitem o

d) Vasos sanguíneos ${ }^{15}$ sinusoidais: pequenos vasos sanguíneos similares a capilares, porém com pequenas aberturas de comunicação com o endotélio. Trombopoetina ${ }^{13}$ : citocina que influencia a diferenciação de megacariócitos e como consequência atua no processo de trombopoiese na formação de PPs. Forças de cisalhamento ${ }^{15}$ : resultado do fluxo sanguíneo diferencial, ou seja a velocidade do fluxo de sangue é mais elevada no centro dos vasos e diminui no sentido da parede do vaso.

e) Receptores Toll-like ${ }^{1}$ : Os receptores TL são uma família de receptores de reconhecimento, são expressos por fagócitos, tais como neutrófilos, macrófagos e células dendríticas, e promovem a ativação do sistema imune em resposta ao reconhecimento de sítios específicos - motivos conservados expressos pelos patógenos. 
estudo da hemostasia e a formação de trombos em células vivas, e a ativação dos eventos de sinalização em células vivas. Estas novas tecnologias vão colaborar para a compreensão do complexo papel das plaquetas na formação de trombos fisiológicos e patológicos, assim como no desenho de drogas antitrombóticas mais eficazes ${ }^{23}$.

\section{PAPÉIS TRADICIONAIS E NÃO TRADICIONAIS DAS PLAQUETAS}

Plaquetas são células efetoras da hemostasia. Uma função primária das plaquetas, bem conhecida dos clínicos e investigadores, é limitar a hemorragia após um trauma ou dano vascular, ou seja, a formação do tampão plaquetário. Para tanto, as plaquetas devem ser recrutadas e ativadas. Esses processos são iniciados com a adesão à matriz subendotelial exposta em sítios específicos do endotélio lesado via glicoproteína Ib/V/IX de superfície endotelial, que reconhece o vWF e outros ligantes ${ }^{4}$. Uma variedade de integrinas da superfície plaquetária, bem como receptores de colágeno, adere à matriz subendotelial. A ativação das plaquetas via receptores acoplados à proteína $\mathrm{G}$, pode ser iniciada por proteases ou gera endogenamente o tromboxano $\mathrm{A}_{2}$ Os receptores ativados por proteases (PARs) são clivados por trombina, uma serinoprotease, e os outros receptores, não ativados por proteases, reconhecem ADP Outros agonistas rapidamente amplificam e iniciam a adesão, medeiam a agregação e recrutamento de plaquetas adicionais ao sítio da lesão. A ativação celular converte a integrina $\alpha_{\text {IIB }} \beta_{3}$ (glicoproteínaIIb/IIIA - a principal integrina célula-específica em megacariócitos e plaquetas) a um estado conformacional adequado para a ligação ao fibrinogênio, fibrina e outros ligantes, mediando uma agregação homotípica e eventos adicionais de adesão. O tempo é fator limitante, neste cenário onde, cada uma dessas respostas ocorre dentro de segundos a minutos após a ativação ${ }^{4}$.

Em resposta ao enlace da integrina às moléculas de adesão e à ativação por agonistas descrita acima, inicia-se o processo de splicing. O complexo de spliceossomo recrutado nas plaquetas remove precisamente os íntrons do pré-mRNA, e obtém um mRNA maduro que é traduzido em proteína. Esse mecanismo de splicing, totalmente dependente de ativação por agonistas, é uma função não tradicional das plaquetas e demonstra a especialização notável destas células anucleadas na regulação do seu próprio conteúdo de mRNAs e posteriormente do seu conteúdo de proteínas (com complexo de proteassomos e poli-ubiquitina). Embora este mecanismo seja único para as plaquetas, sugere também a diversidade anteriormente não reconhecida sobre os papéis funcionais do spliceossomo em células eucarióticas ${ }^{3} .{ }^{\mathrm{f}}$

Interrupções genéticas e farmacológicas dos processos citados, causam sangramentos, fornecendo clara evidência do crítico papel das plaquetas na fisiologia da hemostasia. Cada passo é um importante alvo para estratégias terapêuticas em doenças trombóticas. Além disso, para a rápida formação da barreira hemostática e o fornecimento de componentes celulares ao molde do coágulo, as plaquetas também medeiam a retração do coágulo. Este é um processo prolongado e amplamente explorado in vitro, onde a estabilização do coágulo dá inicio à sua remodulação ${ }^{24,25}$.

Células hemostáticas endoteliais podem regular rápidas respostas plaquetárias. Pelo menos três sistemas moleculares contribuem para o arsenal antitrombótico do endotélio: o sistema ciclooxigenase/prostaciclina, a síntese do óxido nítrico (NO) a partir da L-arginina e da arginase e o sistema da ecto-adenosina difosfato ${ }^{21}$. Devido as vias endoteliais que regulam a ativação e desativação, as plaquetas foram designadas como células anucleadas exclusivas de depósitos de estruturas subendoteliais e de sítios primários hemostáticos de formação do coágulo (na matriz subendotelial), e consequentemente são repelidas a partir da superfície endotelial intacta. A matriz subendotelial exposta é claramente um sítio preferencial de deposição de plaquetas no fluxo sanguíneo. Porém, há relatos, principalmente em modelos de roedores, de que plaquetas podem aderir a células endoteliais danificadas ou inflamadas. Isso pode acontecer na circulação pulmonar ou em tumores ${ }^{1,16,26}$. As plaquetas ativadas que se acumulam em sítios de dano vascular ou na ruptura dos vasos podem transmitir sinais inflamatórios a células endoteliais, um potencial mecanismo de amplificação na hemostasia, trombose e inflamação ${ }^{5}$.

As plaquetas têm relevante atividade na hemostasia, além das tradicionais e bem conhecidas respostas de adesão, agregação e formação do tampão hemostático. Plaquetas ativadas fornecem uma superfície negativa com a exposição do fosfolipídeo de membrana, fosfatidilserina. Essa exposição regula o processo da coagulação, por controlar a formação de trombina, fornecer sítios de ligação para os fatores Xa e Va, alterar alostéricamente suas atividades proteolítica e de cofator e finalmente atuar na catálise da via extrínseca da cascata da coagulação pelo complexo fator tissular/ fator VIIa. Esse é um passo crítico na propagação e estabilização do coágulo. Há tempos, o sistema da coagulação é discutido como o sistema fisiológico da coagulação, onde as intervenções do sistema da coagulação levam a combinação das anteriormente separadas vias intrínsecas, extrínsecas e via comum. Hoje se sabe que há uma amplificação de sinal e que há a ativação concomitante das vias, uma retroalimentação da catálise da cascata onde o fator limitante é a velocidade de ativação dos fatores da coagulação. As interpretações teórico/didáticas da coagulação levam a um sistema interligando as duas vias com o sistema de contato (superfícies com cargas negativas) que são importantes para conter o sangramento ou mesmo para o reparo vascular ${ }^{27}$.

É vasta a literatura que indica a capacidade crescente pró-inflamatória das plaquetas. Neste cenário, surgem as micropartículas de plaquetas, que são vesículas intactas, de 0,2 a $1 \mu \mathrm{m}$ de diâmetro,

f) Proteassomo ${ }^{4}$ é um complexo de proteínas capaz de degradar praticamente qualquer proteína em oligopeptídeos de sete a nove aminoácidos com consumo de ATP. Ubiquitina ${ }^{4}$ :é uma proteína encontrada nas células eucariotas constituídas por 76 aminoácidos que desempenha uma função importante na regulação de proteínas. Ela marca proteínas indesejadas (proteínas mal enoveladas) para que sejam degradadas pelo complexo de proteínas, os proteassomos. 
que se formam por brotamento da membrana da plaqueta ativa$\mathrm{da}^{5}$ que carregam o fator tissular (ou tecidual) liberado na propagação do coágulo. As plaquetas ativadas e as micropartículas de plaquetas são fontes de fator tecidual e tem sido alvo de discussões e controvérsias ${ }^{28}$. Dentre as discussões estão as micropartículas, ricas em fator tecidual derivadas de monócitos estimulados, que podem se ligar a plaquetas ativadas via PSGL-1 (P-selectin glycoprotein ligand- 1$)^{27}$.

Neste contexto inflamatório podemos ainda citar a participação da plaqueta na interação com o endotélio e com leucócitos, onde ocorre a expressão de moléculas de adesão celular (CAM), como a E-selectina, na superfície da parede dos vasos sanguíneos e em leucócitos presentes no fluxo sanguíneo. O primeiro passo do processo de interação é realizado pela PSGL-1 versus P-selectina e/ou E-selectina. Essa interação resulta no rolamento de leucócitos pela superfície da célula endotelial por uma adesão estável e transmigração das células brancas até o interior do tecido inflamado. Após a exposição da P-selectina na plaqueta ao ligante PSGL-1 na superfície de leucócitos, inicia-se a sinalização intercelular justácrina e a expressão gênica de mediadores inflamatórios liberados por leucócitos (células alvo) ${ }^{30}$.

Em 2006 e 2007, corroborando com essas hipóteses, e de modo inovador, pesquisadores indicaram que plaquetas humanas ativadas sintetizam o fator tecidual e podem também ser fonte primária desta proteína pró-coagulante na hemostasia e na trombose ${ }^{30,31}$. A síntese do fator tecidual se dá exclusivamente por plaquetas ativadas e é regulada por um processo de splicing e de translocação de pré mRNAs. Essas observações têm sido um marco para alterar paradigmas neste campo do conhecimento. Há evidencias de que o fator tecidual pode contribuir para a iniciação e a amplificação do mecanismo da coagulação e, consequentemente, ser sintetizado e exposto por plaquetas ativadas em sítios de hemostasia primária. Em paralelo, resultados demonstram que plaquetas ativadas fornecem sinais que induzem a síntese de fator tecidual também por monócitos, os quais também se acumulam em coágulos e em sítios de danos vascular ${ }^{32}$. Desta forma, as plaquetas ativadas possuem novas atividades identificadas, as quais podem influenciar na formação do coágulo via mecanismos que complementam sua rápida deposição ao tampão hemostático. Essas atividades ou outras funções inflamatórias das plaquetas, podem fornecer novos alvos moleculares no tratamento de trombose venosa e tromboembolismo ou mesmo no dano agudo pulmonar ${ }^{12}$.

A ideia de que plaquetas são conhecidas por suas imediatas atividades hemostáticas, é também uma visão restrita de suas funções fisio-patológicas. Como salientado, elas possuem atividades não tradicionais que são secundárias ao coágulo e à manutenção da integridade tecidual, mas, não menos importantes.
Sendo notavelmente efetoras nos processos inflamatório e imune e respondendo a estímulos externos derivados de outras células, as plaquetas estão envolvidas na inflamação e à hemostasia. Tais propriedades podem ser expressão de uma capacidade evolutiva conservada que foi mantida quando a defesa do hospedeiro era restrita a uma, ou a um número pequeno de atividades, antimicrobianas ou de reparo ${ }^{1}$

As funções não tradicionais das plaquetas não param de surgir. Assim, nos anos 2004 e 2005, Shiraki ${ }^{33}$, Cognasse ${ }^{34}$ et al. descobriram receptores funcionais Toll-like em ratos e humanos, receptores esses que reconhecem lipopolissacarídeos bacterianos e outros produtos microbianos. A expressão de receptores Toll-like representa uma nova faceta no repertório de interação da plaqueta em resposta à presença de microorganismos e seus sinais moleculares, contribuindo assim para a efetiva função antimicrobiana ${ }^{1}$. Além disso, os receptores Toll-like modulam a sinalização inflamatória e respostas trombóticas na sepse e em outras condições patológicas, como o câncer ${ }^{1,34}$. Outros sistemas de transdução de sinais em plaquetas são os ativados por trombina e/ou PAF (platelet activating factor), que também ligam hemostasia e inflamação sob condições fisio-patológicas ${ }^{16}$.

Além da sinalização dos receptores Toll-like, as plaquetas têm outras habilidades no processo inflamatório. Elas podem liberar uma variedade de citocinas e quimiocinas, fornecendo mecanismos rápidos na resposta inflamatória aguda. $\mathrm{E}$ ainda, as plaquetas rapidamente sintetizam o eicosanóide tromboxano $\mathrm{A}_{2}$, que modula a resposta imune e a hemostasia ${ }^{4}$.

Inesperadamente, as plaquetas também sintetizam uma citocina inflamatória reguladora pleiotrópica com múltiplas ações de reparo, a interleucina $1 \beta$ (IL-1 $\beta$ ). A IL- $1 \beta$ sintetizada por plaquetas ativadas pode induzir respostas inflamatórias em células endoteliais humanas. Sua síntese em plaquetas se dá pelo processo de splicing e translocação do pre-mRNA via sinal dependente, como a ativação por trombina ${ }^{1} .^{\mathrm{g}}$

Ainda relacionada à resposta imune, as plaquetas também tem a capacidade de alterar direta ou indiretamente a ontogênese, função de macrófagos e células dendríticas ${ }^{4,7}$. Em resumo, as plaquetas podem influenciar no espectro inflamatório e nas respostas imune inata e adquirida, através de seus sistemas moleculares e sinalização justácrina ${ }^{1,4}$. ${ }^{.}$

Na resposta imune adaptativa ou em sítios inflamatórios, há a ativação de plaquetas quiescentes na circulação sanguínea, com consequente agregação plaquetária, exposição na superfície plaquetária de P-selectina, secreção de quimiocinas, citocinas, fatores de crescimento e ainda há a síntese de mediadores lipídicos como tromboxano $\mathrm{A}_{2}$ e PAF. E em resposta a esses mediadores lipídicos as plaquetas sintetizam rapidamente IL-1 $\beta$ por via pós

g) Ação pleiotrópica ${ }^{1}$ : ação múltipla

h) Sinalização Justácrina: ${ }^{5}$ sinalização que requer contato físico entre as células envolvidas

PSGL-129: uma glicoproteína encontrada em células brancas do sangue e em células endoteliais que se ligam a P-selectina, uma molécula de adesão celular. O PSGL-1 pode se ligar aos três membros da família selectinas, a selectina endotelial (E-selectina), a selectina de leucócitos (L-selectina) e a selectina de plaquetas (P-selectina) porém, liga-se com mais afinidade a P-selectina. 
transcrição, e essa citocina pode permanecer associada a célula ou pode ser liberada em solução ou em associação a microvesículas ${ }^{1,4}$.

Em sistemas in vitro, quando sintetizada por plaquetas ativadas a IL-1 $\beta$ é direcionada e depositada aos coágulos de fibrina. Se isso ocorre in vivo, coágulos e trombos podem agir como reservatórios locais de citocinas, e a IL-1 $\beta$ pode sinalizar para células endoteliais humanas a síntese de moléculas de adesão, as quais modulam a ativação e o acúmulo de PMN (células polimorfonucleadas). As plaquetas podem também induzir respostas inflamatórias por expor o ligante CD40 (CD40L) a uma proteína do tipo fator de crescimento do tipo TNF- $\alpha$ (fator de necrose tumoral), que é reconhecida pelo receptor CD40 na superfície de células endoteliais ${ }^{1,4}$.

\section{PLAQUETAS ATIVADAS SINTETIZAM MEDIADORES}

A ideia de que plaquetas são apenas estocadoras de proteínas e de mediadores bioativos já está no passado. Como já mencionado, as plaquetas contêm uma carga de mRNA herdada dos megacariócitos e são capazes de sintetizar suas próprias proteínas e outras moléculas ${ }^{1}$.

Plaquetas sintetizam tromboxano $\mathrm{A}_{2}$ de forma rápida e eficaz a partir da via do ácido araquidônico, através da ciclooxigenase e também da via da lipoxigenase para metabolizar o aracdonato a 12-hidroxi-eicosanoide. $\mathrm{O}$ tromboxano $\mathrm{A}_{2}$ tem atividade pró-trombótica e pró-inflamatória, e a lipoxigenase plaquetária pode mediar a produção de lipoxinas em interações plaqueta-neutrófilo ${ }^{4}$.

As plaquetas ainda sintetizam PAF, e além de lipídeos, plaquetas ativadas produzem ânion superóxido e outras espécies reativas de oxigênio (ROS - reactive oxigen species) via NADPH oxidase. A geração do ânion superóxido, por plaquetas ativadas, leva ao acúmulo de plaquetas no trombo em crescimento e pode prejudicar as atividades inibitórias do NO localmente liberado pelas células endoteliais. A capacidade de sintetizar tromboxano $\mathrm{A}_{2}$, ROS e lipoxinas fornecem mecanismos pelos quais as plaquetas ativadas podem modificar os eventos vasoativos, inflamatórios e hemostáticos ${ }^{4}$.

Enquanto a síntese de lipídeos biologicamente ativos e a geração de ROS estão estabelecidas como funções de plaquetas ativadas, recentemente se descobriu que plaquetas maduras e circulantes sintetizam proteínas em resposta à ativação por trombina $\mathrm{e}$ outros sinais fisiológicos de ativação ${ }^{4}$.

Em resumo, esta nova função plaquetária de sintetizar proteínas ocorre por um repertório pós-transcrição herdado dos megacariócitos, consistente com o fato de que as plaquetas são células anucleadas e não transcrevem mRNAs (com exceção da transcrição mitocondrial) $)^{3}$.

O diferencial atribuído à síntese de proteínas específicas por plaquetas é que o processo ocorre em plaquetas ativadas e não em plaquetas em repouso, ou seja, a tradução em plaquetas é sinal dependente $e^{1,3,26}$.
O primeiro exemplo de que esse processo ocorre em plaquetas foi a síntese de $\mathrm{BCl}-3$ (B cell lymphoma-3) por plaquetas humanas ativadas, tal processo atua sobre o controle especializado de tradução por uma quinase de mamífero mTOR (mammalian target of Rapamycin). A síntese da BCl-3 em plaquetas humanas ativadas auxilia na regulação da retração do coágulo. Além disso, é possível que a tradução e a síntese sinal dependente da $\mathrm{BCl}-3$, por plaquetas, podem modificar o depósito de fibrina e o trombo intravascular, principalmente em danos pulmonares. Um importante ponto da síntese da BCl-3 e de outras proteínas chaves é o fato de ser iniciado rapidamente por plaquetas ativadas ${ }^{35}$.

A síntese acelerada de produtos proteicos é uma vantagem biológica de controle da tradução dos mRNA anteriormente transcritos em megacariócitos. Isso é claramente vantajoso às plaquetas, uma vez que estas células são de resposta rápida em ferimentos e na hemostasia. Além disso, a tradução (sinal dependente) de novas proteínas por plaquetas continua por várias horas, indicando que a resposta dessas células anucleadas não está limitada à adesão, à agregação e à degranulação dos primeiros minutos da hemostasia ${ }^{1,3}$.

Com o advento da análise proteômica em plaquetas, algumas de suas funções no sistema imune, antes desconhecidas, estão cada vez mais em evidência. Por exemplo, a análise proteômica tem demonstrado que plaquetas tem habilidade de secretar mais de 300 diferentes proteínas após a sua ativação por trombina, algumas das quais estão a interleucina-1 (IL-1), receptores Toll-like e CD40L, proteínas envolvidas em outros processos além da coagulação sanguínea ${ }^{1,36}$. Portanto, a compreensão de toda a gama de funções plaquetárias está se tornando mais complexa e necessária.

Mediadores bioativos parácrinos e a expressão de moléculas de adesão por plaquetas ativadas facilitam tanto interações homotípicas (plaqueta-plaqueta) como interações heterotípicas (plaquetas-populações celulares do sistema imune) e iniciam assim respostas funcionais espacialmente localizadas, na forma justácrina. Por exemplo, plaquetas ativadas medeiam a adesão de neutrófilos ao endotélio e também regulam suas funções pro-inflamatórias. Outro exemplo é a interação de plaquetas ativadas com células dentríticas estimulando a liberação de citocinas inflamatórias em sítios de lesão tecidual. Com base nessas novas facetas das funções das plaquetas bem como seus papéis tradicionais na hemostasia, estas células anucleadas são cruciais mediadores na comunicação celular em processos inflamatórios. Além disso, embora as plaquetas expressem poucas moléculas integrais de membrana do tipo MHC (major histocompatibility complex), elas podem adsorver (reter a superfície) moléculas solúveis do tipo MHC de classe I derivados do plasma, implicando por exemplo em reações pós transfusionais ${ }^{1}$.

Healy et al. ${ }^{37}$ analisaram pacientes com infarto do miocárdio e verificaram diferenças no perfil de mRNA plaquetário quando comparado à pacientes com doença coronariana estável. Uma análise similar pode ser útil em amostras de indivíduos com dano 
agudo pulmonar e pode relacionar predisposições como sepse, na qual a ativação plaquetária é frequente e pode ser ubíqua.

Doenças inflamatórias e algumas desordens pulmonares causam acúmulo de plaquetas no pulmão, e remotas lesões teciduais e condições sistêmicas como a sepse podem ativar plaquetas na circulação $0^{4,26}$.

\section{LESÃO PULMONAR AGUDA ASSOCIADA À TRANSFUSÃO}

Transfusion-Related Acute Lung Injury (TRALI) é definida como uma síndrome de edema pulmonar não cardiogênica e relatada temporariamente, após transfusão de produtos do sangue, e que usualmente ocorre entre 30 minutos e 6 horas após a transfusão de hemocomponentes que contêm plasma, incluindo transfusões de plaqueta são relacionadas à TRALI. Estudos clínicos e experimentais indicam que a TRALI é causada pela infusão de anticorpos anti-neutrófilos e de lipídeos biologicamente ativos, em plasma para transfusão ou em concentrado de plaquetas, atuando juntamente com os primeiros PMNs aderidos ${ }^{1,38}$.

O significado da TRALI na medicina transfusional ressurgiu recentemente, por ter sido classificada como uma das principais causas de mortes relacionadas à transfusão $0^{1,38}$.

Estudos sobre o papel das plaquetas na TRALI mostram a ligação com os receptores Toll-like que podem levar à liberação de CD40 solúvel. Khan et al. (apud Semple, Italiano e Freedman ${ }^{1}$ ) sugerem que, em concentrados de plaquetas estocados em bancos de sangue, o CD40 solúvel pode promover ativação de neutrófilos pulmonares através da interação com o receptor CD40, contribuindo assim para a TRALI. Além disso, Looney et al., concluíram através de experimentos in vivo utilizando ratos, que concentrados de plaquetas são fontes de lipídeos que podem atuar no dano agudo pulmonar, porém, não está claro como plaquetas transfundidas são ativadas na circulação. Cogita-se que, ocorra autoativação ou ativação por produtos endógenos plaquetários, como a esfingosina 1-fosfato (S1P), um lisofosfolipídeo liberado pela plaqueta ativada, e citocinas inflamatórias como TGF- $\beta$, IL-1 $\beta$ e IL-8, que podem ampliar a ativação de concentrados de plaquetas estocados em serviços de hemoterapia. Uma vez ativadas, as plaquetas participam diretamente no dano pulmonar, e se houver a ativação de PMNs por anticorpos anti-neutrófilos e/ou por mediadores lipídicos derivados de plaquetas, essas células contribuem para o dano na membrana do capilar alveolar ${ }^{4}$.

Com base nos dados atuais há a necessidade de investigação sobre a participação de plaquetas nesta síndrome, estudos estes que serão fundamentais para garantir a eficácia e segurança das transfusões de sangue.

\section{PLAQUETAS E O CÂNCER}

A hipótese de que as células tumorais podem manipular a habilidade das plaquetas a regularem a angiogênese por causarem um "hijacking" - "sequestro" plaquetário à sítios secundários tumorais é amplamente discutida ${ }^{26}$. Além da sua participação na angiogênese há evidências que plaquetas dão suporte à metástase tumoral. A ativação plaquetária e a ativação do sistema de coagulação têm papéis cruciais na progressão do câncer. No sistema circulatório, as plaquetas atuam como "guardiãs" das células tumorais evitando sua identificação e eliminação pelo sistema imune. Neste sentido, as plaquetas promovem o transporte, parada e aderência das células tumorais ao endotélio, dando suporte ao estabelecimento de sítios tumorais secundários ${ }^{16}$.

Pacientes com câncer apresentam frequentemente sinais de trombose, e esses sinais se tornam mais severos de acordo com a progressão da doença e estágios de metástase. Diversas formas de tromboses incluem coagulação intravascular disseminada, tromboflebite migratória e embolismo pulmonar indicando ativação plaquetária aberrante. Desta maneira, se esses eventos trombóticos não são detectados, podem-se identificar anomalias nos parâmetros da coagulação que estão aumentados em pacientes com câncer, bem como está aumentada a renovação de plaquetas $^{16}$.

A metástase a órgãos distantes do sítio primário do tumor depende de interações entre as células tumorais e o microambiente do hospedeiro, como a circulação, vasos linfáticos e tecidos alvo. Para que as células tumorais alcancem outros sítios há o envolvimento de células do sangue, componentes do sistema da coagulação, células estromais e a matriz extracelular. Dentre as células do sangue que contribuem para a metástase estão as células endoteliais, plaquetas, linfócitos, macrófagos, mastócitos e células progenitoras derivadas da medula óssea ${ }^{16}$.

No processo de angiogênese e remodelação vascular também há a participação de plaquetas, como já mencionado. A formação de vasos dentro de tumores é um mecanismo necessário para a progressão tumoral a fim de prevenir a hipoxia induzida pelo crescimento, estagnação e necrose tumoral. Além disso, a vascularização dentro de um tumor é um portal em que as células tumorais podem entrar na circulação para se disseminar. Neste cenário, as plaquetas podem estabilizar o crescimento de vasos durante o desenvolvimento do tumor e assim contribuir para a sua progressão. Para que ocorra a expansão de tumores e metastases, ocorre o recrutamento de novos vasos para garantir nutrientes e oxigênio para o futuro crescimento da lesão. Contribuindo

i) Ubíqua: que pode estar em toda parte = onipresente, geral, sistêmico.

j) Coagulação intravascular ${ }^{15}$ disseminada: Ativação patológica da coagulação (formação de coágulos) mecanismos que conduz à formação de pequenos coágulos nos vasos sanguíneos.

Tromboflebite ${ }^{15}$ migratória: Malignidade associada ao estado de hipercoagulabilidade, levando à formação de espontâneos coágulos ricos em plaquetas em veias ou em qualquer lugar do corpo, são formados e destruídos dinamicamente.

Embolismo pulmonar ${ }^{15}$ : Obstrução da artéria principal do pulmão ou de um de seus ramos por um coágulo sanguíneo rico em plaquetas que se originou na circulação venosa e pode ser deslocado a partir de onde inicialmente foi formado. 
para esse processo estão as plaquetas ativadas que liberam fator de crescimento endotelial vascular (VEGF), promovendo assim a angiogênese ${ }^{26}$.

Muitas das funções não hemostáticas das plaquetas podem resultar a partir da sua capacidade de estocar numerosos fatores bioativos em seus grânulos intracelulares. Essas moléculas podem ser liberadas para a circulação sanguínea, ou podem ser translocadas para a superfície da plaqueta durante a ativação plaquetária para a regulação do processo de angiogênese. Esses fatores podem ser anti-angiogênicos como a angiopoetina 1 (ANGPT1, também conhecida como ANG1), e o já mencionado fosfolipídeo esfingosina 1-fosfato (S1P), serotonina, trombospondina 1 (THBS1); ou pró-angiogênicos como VEGF, o fator de crescimento epidermal (EGF), o fator de crescimento básico de fibroblasto (FGF2), ou como citocinas IL-1 $\beta$ e IL-8 e proteases (como as metallo-proteases de matriz MMP-2 e MMP-9 ${ }^{26}$.

A ativação de plaquetas pode ocorrer localmente dentro do ambiente vascular tumoral, ou de forma sistêmica, como é observado em pacientes com câncer de próstata, mama, pulmão, colon e tumores gástricos. A vascularização do tumor com vazamento pode expor proteínas de matriz como o colágeno, um potente ativador plaquetário $^{36}$.

As plaquetas também têm sido citadas por atuarem localmente em vasos sanguíneos através da liberação de seus fatores bioativos. O interessante nesse processo é que os fatores a serem liberados e a intensidade com que isso acontece depende do estímulo dado pelo ambiente à plaqueta. Como por exemplo, grânulos plaquetários carregados com VEGF são seletivamente liberados após a ativação de receptores ativados por proteases (PAR-1) e grânulos contendo endostatina (fator anti-angiogênico) são liberados após a ativação de PAR-4. Esses achados não só explicam uma função importante das plaquetas na hemostasia, mas também sugerem que as células tumorais podem usar as plaquetas como balanço no ambiente angiogênico ${ }^{16}$.

Estudos futuros podem mostrar que a multiplicidade de fatores de crescimento e citocinas liberadas dos grânulos de plaquetas afetam diretamente a sobrevivência e proliferação das células tumorais, bem como o recrutamento de células inflamatórias ao microambiente de sítios secundários tumorais. Assim, a investigação da participação das plaquetas, os seus receptores de superfície, e seus mediadores liberados e a influência crítica sobre as vias de coagulação, como o aumento na atividade do fator X e trombina, vão auxiliar a demonstrar os mecanismos de metástase tumoral, bem como o desenvolvimento e a estabilidade vascular que dão suporte ao crescimento tumoral ${ }^{26,36,39}$.

As mudanças necessárias para o processo de disseminação de células tumorais durante a metástase fornecem questões desafiadoras para resolver e compreender a complexidade do envolvimento das plaquetas em diferentes estágios da progressão do câncer. Diante disso, os pesquisadores Gay e Felding-Habermann ${ }^{16}$ sugerem algumas questões, como por exemplo, "quais estágios da progressão tumoral são afetados pelas funções hemostáticas das plaquetas? Quando as funções adesivas das plaquetas dão suporte ou influenciam a progressão tumoral? Quando ocorre e como é o envolvimento das plaquetas no processo inflamatório?" Novos conceitos incluem a identificação e o domínio da biologia dos nichos tumorais, e como as plaquetas podem contribuir para o seu desenvolvimento em órgãos distantes. Talvez essas questões possam estar relacionadas às funções plaquetárias durante o processo de recrutamento das células progenitoras, derivadas da medula óssea. Além é claro, sobre as incontáveis funções dessas células anucleadas, nos processos tumorais de angiogênese e metástase $\mathrm{e}^{16,39}$.

\section{CONCLUSÕES E OBSERVAÇÕES}

Há cinquenta anos, as plaquetas eram consideradas como o "pó de células vermelhas" e passaram de fragmentos celulares a células anucleadas, e são vistas como participantes integrais dos processos tradicionais da hemostasia e não tradicionais como os processos inflamatórios, imunes e no desenvolvimento e progressão tumoral.

Diante dessa revisão, podemos sugerir que a investigação da função plaquetária prevê uma melhor compreensão dos mecanismos moleculares que associam as plaquetas aos processos dinâmicos do organismo, e como consequência, podem-se identificar novas e promissoras abordagens clínicas.

\section{REFERÊNCIAS}

1. Semple JW, Italiano JE Jr., Freedman J. Platelets and the immune continuum. Nat Rev Immunol. 2011;11(4):264-74.

2. Gnatenko DV, Dunn JJ, McCorkle SR, Weissmann D, Perrotta PL, Bahou WF. Transcript profiling of human platelets using microarray and serial analysis of gene expression. Blood. 2003;101(6):2285-93.

3. Denis MM, Tolley ND, Bunting M, Schwertz H, Jiang H, Lindemann $\mathrm{S}$, et al. Escaping the nuclear confines: signal-dependent premRNA splicing in anucleate platelets. Cell. 2005;122(3):379-91.

4. Bozza FA, Shah AM, Weyrich AS, Zimmerman GA. Amicus or adversary: platelets in lung biology, acute injury, and inflammation. Am J Respir Cell Mol Biol. 2009;40(2):123-34.
5. Boilard E, Nigrovic PA, Larabee K, Watts GF, Coblyn JS Weinblatt $\mathrm{ME}$, et al. Platelets amplify inflammation in arthritis via collagen-dependent microparticle production. Science. 2010;327(5965):580-3.

6. Italiano JE Jr., Patel-Hett S, Hartwig JH. Mechanics of proplatelet elaboration. J Thromb Haemost. 2007:5(suppl.1):18-23.

7. Mason KD, Carpinelli MR, Fletcher JI, Collinge JE, Hilton AA, Ellis $\mathrm{S}$, et al. Programmed anuclear cell death delimits platelet life span. Cell. 2007;128(6):1173-86.

8. Varela FJ, Maturana HR. The tree of knowledge: the biological roots of human understanding, revised edition. Shambhala Publications, 1992 
9. Geddis AE, Kaushansky K. Immunology. The root of platelet production. Science. 2007;317(5845):1689-91

10. Junt T, Schulze H, Chen Z, Massberg S, Goerge T, Krueger A, et al. Dynamic visualization of thrombopoiesis within bone marrow. Science. 2007;317(5845):1767-70.

11. Bierman HR. The hematologic role of the lung in man. Am J Surg $1955 ; 89(1): 130-40$

12. O'Sullivan BP, Michelson AD. The inflammatory role of platelets in cystic fibrosis. Am J Respir Crit Care Med. 2006;173(5):483-90.

13. Patel SR, Hartwig JH, Italiano Jr JE. The biogenesis of platelets from megakaryocyte proplatelets. J Clin Invest 2005;115(12):3348-54

14. Zucker-Franklin D, Philipp CS. Platelet production in the pulmonary capillary bed: new ultrastructural evidence for an old concept. Am J Pathol. 2000;157(1):69-74

15. Rivera J, Lozano ML, Navarro-Nunez L, Vicente V. Platelet receptors and signaling in the dynamics of thrombus formation. Haematologica. 2009;94(5):700-11

16. Gay LJ, Felding-Habermann B. Contribution of platelets to tumour metastasis. Nat Rev Cancer. 2001;11(2):123-34.

17. George JN. Platelets, derived from megakaryocte cytoplasm, have a critical role in normal haemostasis, and in thrombotic disorders. Lancet. 2000;355(9214);1531-39.

18. Cupit LD, Schmidt VA, Gnatenko DV, Bahou WF. Expression of protease activated receptor 3 (PAR3) is upregulated by induction of megakaryocyte phenotype in human erythroleukemia (HEL) cells. Exp Hematol. 2004;32(10):991-9.

19. Gay LJ, Felding-Habermann B. Platelets alter tumor cell attributes to propel metastasis: programming in transit. Cancer Cell. 2011;20(5):553-4.

20. Ruggeri ZM, Mendolicchio GL. Adhesion mechanisms in platelet function. Circ Res. 2007;100(12):1673-85.

21. Davi G, Patrono C. Platelet activation and atherothrombosis. N Engl J Med. 2007;357(24):2482-94.

22. Prandoni P. Links between arterial and venous disease. J Intern Med. 2007;262(3):341-50.

23. Furie B, Furie BC. Mechanisms of thrombus formation. N Engl J Med. 2008;359(9):938-49.

24. Parise LV SS, Shet AS, Coller BS. Platelet morphology, biochemistry and function. $7^{\text {th }}$ edn, New York: 2006.

25. Weyrich AS, Denis MM, Schwertz H, Tolley ND, Foulks J, Spencer E. mTOR-dependent synthesis of $\mathrm{Bcl}-3$ controls the retraction of fibrin clots by activated human platelets. Blood. 2007;109(5):1975-83.
26. Battinelli EM, Markens BA, Italiano JE Jr. Release of angiogenesis regulatory proteins from platelet alpha granules: modulation of physiologic and pathologic angiogenesis. Blood. 2011;118(5):1359-69.

27. Mackman N, Tilley RE, Key NS. Role of the extrinsic pathway of blood coagulation in hemostasis and thrombosis. Arterioscler Thromb Vasc Biol.2007;27(8):1687-93

28. Morel O, Toti F, Hugel B, Bakouboula B, Camoin-Jau L, DignatGeorge F, et al. Procoagulant microparticles: disrupting the vascular homeostasis equation? Arterioscler Thromb Vasc Biol. 2006;26(12):2594-604.

29. Schwertz H, Tolley ND, Foulks JM, Denis MM, Risenmay BW, Buerke $\mathrm{M}$, et al. Signal-dependent splicing of tissue factor premRNA modulates the thrombogenicity of human platelets. J Exp Med. 2006;203(11):2433-40.

30. Weyrich AS, Lindemann S, Zimmerman GA. The evolving role of platelets in Inflammation. J Thromb Haemost. 2003;1(9):1897-905.

31. Panes O, Matus V, Saez CG, Quiroga T, Pereira J, Mezzano D. Human platelets synthesize and express functional tissue factor. Blood. 2007;109(12):5242-50.

32. Steiner S, Seidinger D, Huber K, Kaun C, Minar E, Kopp CW. Effect of glycoprotein Ilb/IIla antagonist abciximab on monocyte-platelet aggregates and tissue factor expression. Arterioscler Thromb Vasc Biol. 2003;23(9):1697-702.

33. Shiraki R, Inoue N, Kawasaki S, Takei A, Kadotani M, Ohnishi Y, et al. Expression of Toll-like receptors on human platelets. Thromb Res. 2004;113(6):379-85

34. Cognasse F, Hamzeh H, Chavarin P, Acquart S, Genin C, Garraud O. Evidence of toll-like receptor molecules on human platelets. Immunol Cell Biol. 2005;83(2):196-8

35. Weyrich AS, Dixon DA, Pabla R, Elstad MR, Mclntyre TM, Prescott $\mathrm{SM}$, et al. Signal-dependent translation of a regulatory protein, $\mathrm{Bcl}-3$, in activated human platelets. Proc Natl Acad Sci USA. 1998;95(10):5556-61.

36. Coppinger J, Fitzgerald DJ, Maguire PB. Isolation of the platelet releasate. Methods Mol Biol. 2007;357:307-11.

37. Healy AM, Pickard MD, Pradhan AD, Wang Y, Chen Z, Croce K. Platelet expression profiling and clinical validation of myeloidrelated protein-14 as a novel determinant of cardiovascular events. Circulation. 2006;113(19):2278-84.

38. Looney MR, Gropper MA, Matthay MA. Transfusion-related acute lung injury: a Review. Chest. 2004;126(1):249-58.

39. Psaila B, Lyden D. The metastatic niche: adapting the foreign soil. Nat Rev Cancer. 2009;9(4):285-93. 